gave no growth; in 26 out of 56 urines there had been recent antibacterial therapy, and in the remaining 30 there had been recent surgery (see table). It was possible to identify organisms without difficulty in only 21 out of 50 urines $(42 \%)$ when subcultures were taken directly from the slide. This was due to the presence of mixed growth not readily detectable on the small area of the slide, when growth was heavy.

Diagnosis of 30 Patients with Sterile Pyuria Who Had Not Received Antibacterial Therapy

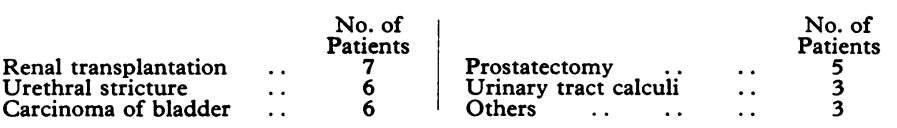

\section{Discussion}

This study has shown that the Uricult dip-slide used in a urological and transplant unit gave results that were identical with those obtained by standard methods in $87 \%$ of cases, and even when there was disagreement $(13 \%)$ the tendency was for the dip-slide method to err on the side of false-positive rather than false-negative results, using the standard plate method as the criterion of correctness. Serious discrepancy was noted in only $3 \%$.

Pyuria was absent in most cases in which bacteriological cultures proved to be negative, and in the cases in which sterile pyuria was found antibacterial therapy or recent urological surgery could be indicted as the cause. The absence of significant pyuria in more than $50 \%$ of cases with significant bacterial growth could imply that microscopy of the urine is not essential in cases of urinary tract infection. Indeed it has been stated (Kass, 1956) that high bacterial concentrations alone are synonymous with urinary tract infection and that treatment should be instituted on this basis. However, we prefer first to obtain confirmation by repeated positive cultures.

Apart from the fact that the dip-slide technique has been shown to be invaluable for use in domiciliary practice, particularly because the slides can be sent by post to the bacteriology laboratory, the present study has confirmed its reliability as a screening procedure in a hospital urological unit. A preliminary dip-slide examination reduces the laboratory work load by screening off negative urines; in those cases in which there is a significant growth further investigations by standard methods can be instituted. Outpatients can present a special problem when a second specimen of urine is required in cases with a positive dip-slide. It is possible for definitive bacteriology to be done by subculturing the colonies from the dip-slide if a second specimen of urine is not available. As mixed cultures frequently occur, however, and preliminary purification is sometimes necessary, this means that the laboratory work load will be increased rather than decreased, defeating the original object of the method. It is probably better, therefore, to use the Uricult dip-slide primarily as a screening procedure unless subsequent urine specimens are not available.

We are most grateful to Mr. R. A. Lambert, chief technician in the department of bacteriology, for his help in reading the Uricult slides and the plates. We also thank Dr. J. Moodie, of Bristol Laboratories, Slough, for providing the Uricult slides.

\section{References}

Arneil, G. C., McAllister, T. A., and Kay, P. (1970). Lancet, 1, 119 Guttmann, D., and Naylor, G. R. E. (1967). British Medical fournal, 2,343 Kass, E. H. (1956). Transactions of the Association of American Physicians, $69,56$.

Mackey, J. P., and Sandys, G. H. (1965). British Medical Fournal, 2, 1286. Parsons, V. (1972). In preparation.

\title{
Correction of Adverse Reponse to Suxamethonium of Susceptible Pigs
}

\author{
DAVID LISTER
}

British Medical fournal, 1973, 1, 208-210

\section{Summary}

The adverse response to suxamethonium in susceptible pigs has been shown to be associated with changes in serum free thyroxine index. Pyrexia and acidosis can be controlled by the cautious administration of L-triiodothyronine (T-3). Successful correction has been achieved in eight episodes, and in six of these, where it was intended, rapid, uneventful, and complete recovery occurred.

\section{Introduction}

In the course of investigating the hyperpyrexic response to suxamethonium in over a hundred susceptible pigs, we showed

\footnotetext{
Agricultural Research Council, Meat Research Institute, Langford, Bristol BS18 7DY

DAVID LISTER, B.SC., PH.D., Principal Scientific Officer
}

that the initial response and its subsequent development were associated with fluxes in the free thyroid hormone as represented by the free thyroxine index in the serum (Lister and Lucke, 1972). All the animals suffered an immediate and noticeable fall in their relatively high serum free thyroxine index, which is the reverse of the change often found during anaesthesia (Oyama et al., 1969). The subsequent pattern of the response depended on the extent to which restoration of the usual free thyroxine index was accomplished. If there was little or no increase in the lowered value for serum free thyroxine index after suxamethonium challenge, death occurred relatively quickly with only moderate pyrexia and acidosis, and there was no evidence of rigor of the musculature. If serum free thyroxine index was increased to a greater extent the acidosis was progressive (blood $\mathrm{pH}<6.6$ and $\mathrm{PCO}_{2}>200 \mathrm{~mm} \mathrm{Hg}$ ), hyperpyrexia developed and rigor occurred usually some time before, but always by the time of death. In all cases the serum free thyroxine index at death was low or falling.

This preliminary note, which outlines the general principles by which the successful correction of the suxamethonium response in eight pigs has been achieved by the administration of thyroid hormone, is prompted by the urgent need to define the aetiology and provide empirically based treatment for this characteristically fatal response in human patients. 


\section{Experimental Method}

Eight pigs of the Pietrain breed weighing 50-60 kg were anaesthetized by using a standard procedure which, in about 130 pigs, had not triggered a hyperpyrexic response. Anaesthesia was induced with thiopentone and maintained, after endotracheal intubation, with nitrous oxide and oxygen by intermittent positive pressure ventilation. Incremental thiopentone was given as necessary.

Suxamethonium (50 mg) was administered as a single injection by way of an ear vein usually about 45 minutes after induction. Thyroid hormone was administered as L-triiodothyronine $(\mathrm{T}-3)$.

Samples of blood were taken for analysis from a cannulated branch of the femoral artery. Blood gases were measured on a blood gas assembly (Radiometer Ltd., Copenhagen, Denmark) and serum samples were analysed for globulin-bound thyroxine and T-3 uptake ratio using methods based on those of Murphy (1965) and Herbert et al. (1965) respectively. Free thyroxine index was calculated by dividing the former by the latter values. Raised values are found in hyperthyroidism and lower values in hypothyroidism.

Rectal temperature was measured with thermistors attached to a Digitec Thermometer (United Systems Corporation, Dayton, Ohio, U.S.A.) and the recordings were printed out automatically at one-minute intervals.

\section{Results and Discussion}

The identification of an adverse response to suxamethonium in our pigs of the Petrain breed is not difficult, for the strain appears to be almost $100^{\prime \prime}$ o sensitive. Within seconds of administration of the drug moderate to violent fasciculations are evident in the musculature, presumably the result of an extended first phase of action of the depolarizing agent. Blood $\mathrm{pH}$ and Pco, values alter, often within minutes, to less than $7 \cdot 1$ units and more than $100 \mathrm{~mm} \mathrm{Hg}$ respectively. Changes in the peripheral circulation may not be evident immediately nor may body temperature rise, although both follow later to a greater or less degree. These changes are typical of those we have observed in our long series of experiments and these, together with the hyperkalaemia and raised serum $\mathrm{Ca}^{++}$and $\mathrm{Mg}^{++}$, are similar to those found in the human response (Britt and Kalow, 1970).

After two to four minutes the fall in serum free thyroxine index has occurred and this can be corrected by 20-50 $\mu \mathrm{g} \mathrm{T}-3$ intravenously. Subsequently it is vital to titrate the administration of T-3 in small doses (not more than $10 \mu \mathrm{g}$ ) against the changes in blood $\mathrm{PCO}_{2}$ and $\mathrm{pH}$. In our pigs a safe maximal dose of T -3 has been $100 \mu \mathrm{g}$ given intravenously in a 10 to 15 minute period, and in most of the cases this has been sufficient to correct the suxamethonium response (fig. 1). The administration of large doses at short intervals has only rapid, fatal consequences with the subject in rigor.

It is particularly important to be cautious in the administration of T-3 in the later stages of correction of the response, for in some animals endogenous thyroid hormone levels may be rising and a high serum free thyroxine index may trigger a second suxamethonium-type response with fatal consequences. Provided the effect of each small dose of T -3 has been evaluated by blood gas analysis and such a reversal identified immediately, it is possible to correct the situation. This has been achieved by stopping the administration of $\mathrm{T}-3$, and by the injection of magnesium sulphate or chloride solution in amounts such that serum $\mathrm{Mg}^{++}$will not exceed 5-6 mM. This may be sufficient to induce muscle relaxation, correct the rising body temperature, and produce an uneventful recovery (fig. 2). In more resistant cases the infusion of $140 \mathrm{mM}$ EDTA or $40 \mathrm{mM}$ EGTA in $10 \%$ dextrose at $0.75 \mathrm{ml} / \mathrm{min}$ has been shown to suppress thyroid hormone production and to lead to the reversal of a developing hyperpyrexia. Postoperatively all animals received $300 \mu \mathrm{g}$
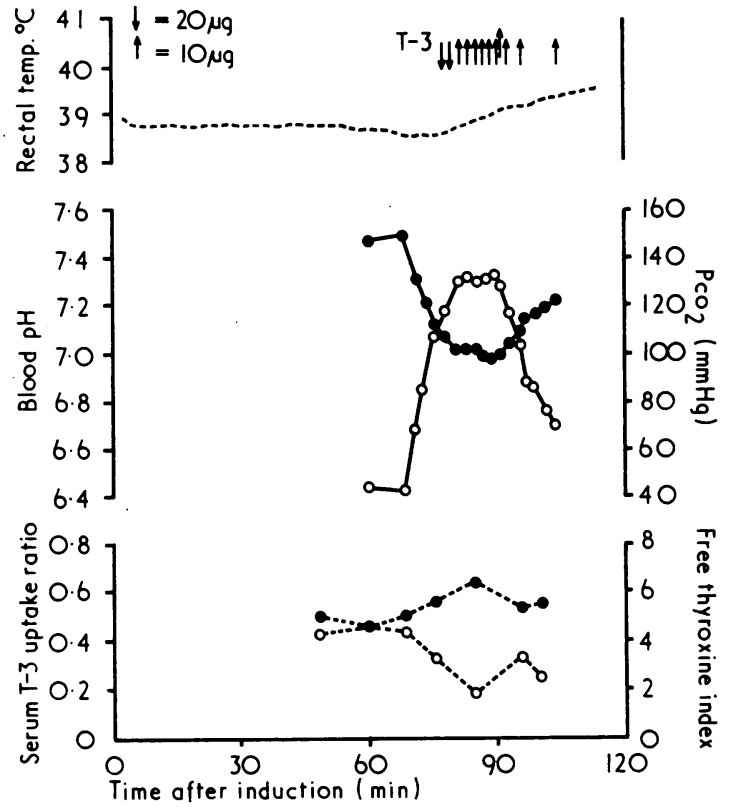

FIG. 1-Correction of suxamethonium response with T-3 alone. - - = Suxamethonium. $-\mathrm{pH}$. $\mathrm{O}-\mathrm{O}=\mathrm{PCO}_{2}$. $-\mathrm{O}=\mathrm{T}-3$ uptake ratio. $O-O=$ Free thyroxine index.
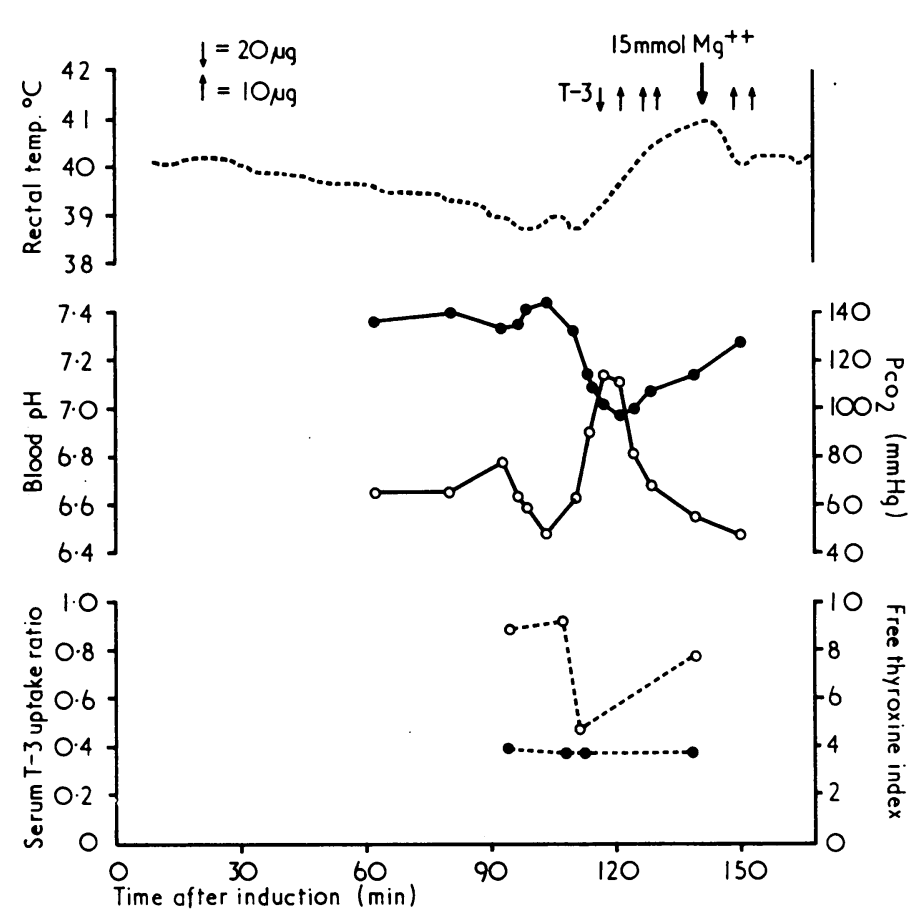

FIG. 2-Correction of suxamethonium response with $\mathrm{T}-3$ and $\mathrm{Mg}^{++}$. See legend to fig. 1 for key to symbols.

L-thyroxine orally, which is slightly less than the calculated daily production of hormone by pigs of that weight.

It is important clinically to identify those animals which require more and those which require less $T-3$ in treatment of the suxamethonium response. There is no substitute for constant monitoring of body temperature, either in the rectum or pharynx, and of blood gases. It has been our experience that the risk of triggering a second response with T-3 was less where the subjects had a low or normal and falling body temperature after induction than where the body temperature was higher and constant.

The six animals in which recovery was intended were comatose postoperatively for several hours, but next day were active 
and eating. Stools tended to be dry for one to two days but subsequently there was complete and uneventful recovery in every case.

The principles on which treatment is based and depends can, therefore, be summarized as follows: (1) the early identification of an adverse reaction to the triggering agent and constant monitoring of the developing acidosis and body temperature; (2) correction of the fall in free thyroxine index; (3) control of the subsequent values for free thyroxine index; and (4) control of high rates of muscle adenosinetriphosphatase activity, which are thought to induce the metabolic changes and which may continue in some refractory subjects if 2 and 3 above are difficult to achieve.

It will be appreciated that the correction of the metabolic acidosis with or without pyrexia after suxamethonium administration is complex, difficult, and not without hazard. The findings of the present report appear to offer some indication of possible control mechanisms which might be of interest to those workers involved in the research of the strikingly similar sensitivity to suxamethonium to be observed in human patients.

I am grateful to my colleagues Miss E. M. Alderson, R. D. Lovell, and P. J. Steel for most expert help. Dr. G. M. Hall assisted at several of the experimental sessions. I also wish to acknowledge helpful discussions with Drs. J. R. Bendall and K. S. Cheah of the M.R.I. and Professor E. Zaimis of the Royal Free Hospital.

L-Triiodothyronine was a gift from Glaxo Laboratories Ltd.

\section{References}

Lister, D., and Lucke, J. N. (1972). In preparation.

Murphy, B. P. (1965). Fournal of Laboratory and Clinical Medicine, 66, 161. Herbert, V., Gottlieb, C. W., Kam-Seng Lau, Gilbert, P., and Silver, S. (1965). Fournal of Laboratory and Clinical Medicine, 66, 814

Oyama, T., Shibatu, S., Matsuki, A., and Kudo, T. (1969). British fournal of Anaesthesia, 41, 103.

Britt, B. A., and Kalow, W. (1970). Canadian Anaesthetist's Society fournal, $17,316$.

\section{MEDICAL MEMORANDA}

\section{"Twin" Intracranial Aneurysms Causing Subarachnoid Haemorrhage in Identical Twins}

\section{B. FAIRBURN}

British Medical fournal, 1973, 1, 210-211

The case histories of a pair of identical twins presenting with subarachnoid haemorrhage from an intracranial aneurysm are reported. Not only did their subarachnoid haemorrhages occur at almost the same age but both their aneurysms were at the same point on the Circle of Willis, at a site where aneurysm formation is comparatively rarely seen. The evidence for a genetic factor in intracranial aneurysms is reviewed.

\section{Case Reports}

Case 1.-A 44-year-old widow was admitted to Oldchurch Hospital on 1 June 1966. Six days earlier she had suddenly complained of severe headache, had vomited, and had lapsed into a stuporous state. Lumbar puncture at another hospital had shown heavily blood-stained cerebrospinal fluid with xanthochromia. On admission she was conscious and rational. She had pronounced neck stiffness. Neurological examination showed no abnormality, apart from bilateral extensor plantar responses. Her blood pressure was $140 / 80 \mathrm{~mm} \mathrm{Hg}$. Bilateral carotid angiogram showed a large rounded aneurysm arising from the supraclinoid part of the right internal carotid artery close to the point of origin of the ophthalmic artery (Fig. 1). Cross-compression showed a good flow between the two sides of the head. On 2 June her right common carotid artery was ligated in the neck under local anaesthesia after 30 minutes' trial clamping of the vessel had produced no adverse effect. She remained well until the fourth postoperative day when she became confused and developed a left hemiparesis. Over the next few days she became completely hemiplegic on the left side with unawareness of these limbs and developed a complete left homonymous hemianopia. Over the period of a further month she became fully alert and rational again and regained some of the power in

Oldchurch Hospital, Romford, Essex

B. FAIRBURN, M.B., F.R.C.S., Consultant Neurosurgeon her left limbs. She was discharged from hospital on 11 August. When last seen as an outpatient in March 1972 she still had a severe spastic weakness of her left upper extremity but her left leg had regained almost full power. Her intellectual functions were intact. Her visual fields were full. She had recently re-married.

Case 2.-The twin sister of Case 1, aged 46, was admitted to Oldchurch Hospital on 4 September 1968. Six days previously she had suddenly developed severe headache and vomiting, and had

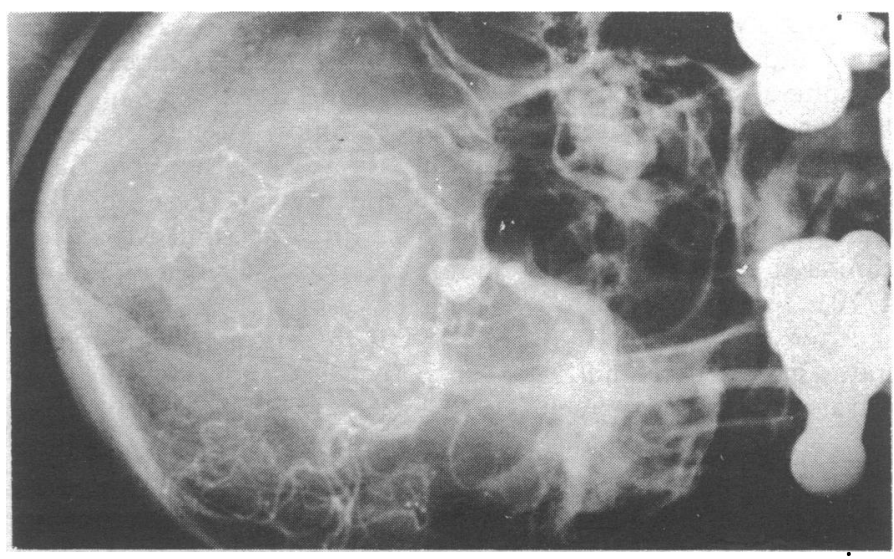

FIG. 1-Oblique angiogram of Case 1

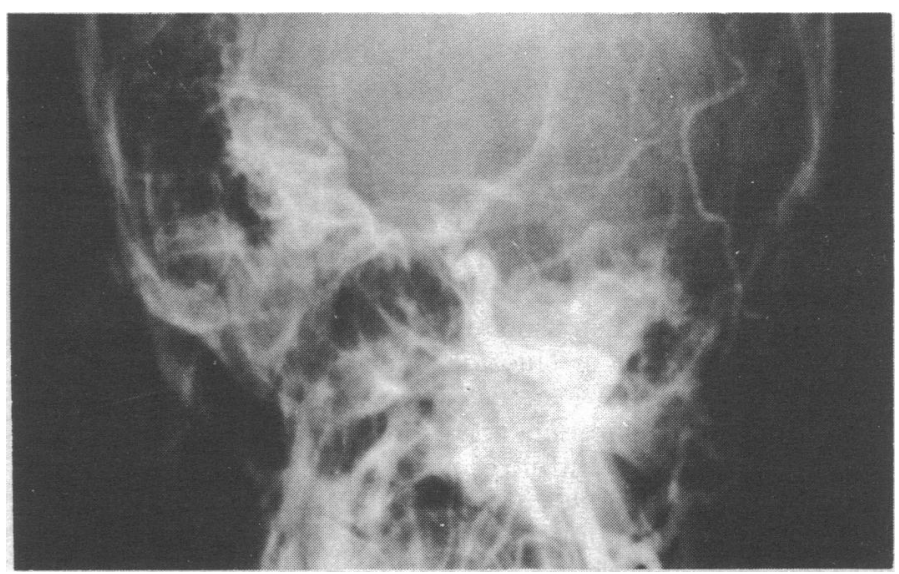

FIG. 2-Oblique angiogram of Case 2. 